\title{
Triptolide suppresses proliferation, hypoxia-inducible factor-1 $\alpha$ and c-Myc expression in pancreatic cancer cells
}

\author{
XIAOLING DING $^{1}$, XIAORONG ZHOU ${ }^{2}$, BO JIANG ${ }^{1}$, QUN ZHAO $^{1}$ and GUOXIONG ZHOU ${ }^{1}$ \\ ${ }^{1}$ Department of Gastroenterology, Affiliated Hospital of Nantong University; \\ ${ }^{2}$ Department of Immunology, Medical School of Nantong University, Nantong, Jiangsu 226001, P.R. China
}

Received March 26, 2014; Accepted January 15, 2015

DOI: $10.3892 / \mathrm{mmr} .2015 .3960$

\begin{abstract}
Triptolide (TL) is known to suppress the proliferation of a number of pancreatic cancer cell lines in vitro. Marked antitumor effects were also observed in a xenograft model of pancreatic cancer. Hypoxia-inducible factor- $1 \alpha$ (HIF-1 $\alpha)$ is highly expressed in pancreatic cancer cells lines. The present study therefore tested the hypothesis that suppression of HIF-1 $\alpha$ is associated with the antitumor activity of TL. Quantitative polymerase chain reaction and western blot analysis were used to determine the level of gene expression. A xenograft tumor model of pancreatic cancer was established in athymic nude mice and the tumor size was measured to evaluate the outcome of TL treatment. Immunohistochemistry was used to detect the expression of HIF-1 $\alpha$ and vascular endothelial growth factor (VEGF), and to assess microvessel density. Microarray was used to investigate gene expression in pancreatic cancer cells following TL treatment. The expression of HIF-1 $\alpha$ was shown to be reduced in pancreatic cell lines following treatment with $\mathrm{TL}$, and this effect occurred in a dose-dependent manner. In a xenograft model of pancreatic cancer, reduced levels of HIF-1 $\alpha$ were also observed in mice that were treated with TL. Furthermore, the expression of VEGF, which is a direct target of HIF-1 $\alpha$, was also suppressed, and the microvessel density of tumor tissues was consequently reduced. A microarray analysis of gene expression was performed in order to investigate the potential mechanisms underlying the antitumor activity of TL. The results showed that 11 genes, including c-Myc, SOX9 and Ets2, were downregulated at an early stage following treatment with TL. A recent study indicated that overexpression of c-Myc in colon cancer cells promotes increased expression of HIF- $1 \alpha$ and VEGF. Therefore, TL may suppress HIF-1 $\alpha$ through a c-Myc-dependent mechanism, which is involved in antitumor effects in mouse models of pancreatic cancer.
\end{abstract}

Correspondence to: Dr Guoxiong Zhou, Department of Gastroenterology, Affiliated Hospital of Nantong University, 21 Xisi Road, Nantong, Jiangsu 226001, P.R. China

E-mail: guoxiong_zhou@163.com

Key words: pancreatic cancer, triptolide, c-Myc, hypoxia inducible factor- $1 \alpha$

\section{Introduction}

The overall 5-year survival rate among patients with pancreatic cancer is $<5 \%$, and it is the fourth leading cause of cancer-related mortality, which affects males and females $(1,2)$. In recent years, there have been important advances in the understanding of the molecular mechanisms underlying the pathogenesis of pancreatic cancer. However, little progress has been made in terms of prevention or treatment, in particular for those individuals with advanced-stage disease $(3,4)$.

A previous study by this groups reported that triptolide (TL), the primary extract of the Chinese herb Tripterygium wilfordii hook, induces apoptosis in pancreatic cancer cell lines in vitro (5). TL also exhibits antitumor effects in numerous types of tumor, including breast, prostate and lung cancer, and sensitizes tumor cells to death induction by a variety of agents, such as Apo2/Trail (6) and tumor necrosis factor- $\alpha$ (7). In the present study, the mechanisms underlying TL-induced cell death and suppression of tumor growth were investigated in a mouse pancreatic cancer xenograft model.

Pancreatic cancer is characterized by hypovasculature, which is due to the fast proliferation of cancer cells and results in a poor blood supply and tumor hypoxia (8). However, malignant cells may undergo genetic or adaptive changes that allow them to survive during oxygen and nutrition deprivation. Hypoxia-inducible factor-1 (HIF-1) is an important regulator under these conditions. HIF-1 is composed of two subunits HIF- $1 \alpha$ and HIF-1 $1 \beta$. HIF- $1 \alpha$ is a unique oxygen-regulated component, which determines HIF-1 activity, such as induction of the expression of a number genes related to tumor angiogenesis, cell proliferation and metabolism $(9,10)$.

In order to investigate the role of HIF-1 $\alpha$ in TL-induced cell death, HIF-1 $\alpha$ gene transcription and protein level in pancreatic cancer cell lines were measured following TL treatment in vitro and in vivo. By microarray analysis of gene expression, TL target genes were searched and the effects of TL on gene expression were confirmed by quantitative polymerase chain reaction (qPCR). The current results suggest that TL possesses strong antitumor effects via suppression of HIF- $1 \alpha$ and other important target genes, including the key oncogene c-Myc in pancreatic cancer cells. 


\section{Materials and methods}

Cell culture and materials. The PANC1, ASPC1 and SW1990 human pancreatic cancer cell lines were purchased from the American Type Culture Collection (Rockville, MD, USA). PANC1 and SW1990 were cultured in Dulbecco's modified Eagle's medium (Invitrogen Life Technologies, Carlsbad, CA, USA) and ASPC1 cells were grown in RPMI 1640 media (Invitrogen Life Technologies). Media were supplemented with $10 \%$ fetal bovine serum (Invitrogen Life Technologies) and cells were grown as monolayers in a humidified atmosphere at $37^{\circ} \mathrm{C}$. Crystalline TL (PG490, purity 99.5\%) was obtained from Shanghai DND Pharm-Technology Co., Inc. (Shanghai, China). The present study was approved by the ethics committee of Nantong University (Nantong, China).

Cell proliferation analysis. Cells $\left(1 \times 10^{4}\right)$ in $200 \mu 1$ medium were seeded into each well of 96-well cell culture plates. Following overnight incubation, cells were treated with 10, 20 and $50 \mathrm{ng} / \mathrm{ml} \mathrm{TL}$. A cell proliferation assay was performed at 6, 12, 24 and $48 \mathrm{~h}$ following incubation, using a Cell Counting kit-8 (Dojindo, Kumamoto, Japan). The cell numbers were evaluated with the absorbance at $450 \mathrm{~nm}$, which was measured on an MR7000 plate reader (Dynatech Laboratories, Chantilly, VA, USA). Control cells were treated with dimethyl sulfoxide (DMSO) only.

Xenograft tumor model and treatments. Athymic nude mice (BALB/c nu/nu, 5-week old females; n=32) were purchased from Shanghai Laboratory Animal Center of Chinese Academy of Science (Shanghai, China). SW1990 cells $\left(10^{7}\right)$ in $100 \mu 1$ phosphate-buffered saline were injected into the backs of BALB/c nude mice. TL was dissolved in $60 \%$ ethanol, $30 \%$ DMSO and $10 \%$ phosphate buffer $(\mathrm{pH} 6.0)$ at a concentration of $1 \mathrm{mg} / \mathrm{ml}$. TL was injected intraperitoneally (IP) into the mice on a daily basis once visible tumors reached $\sim 100 \mathrm{~mm}^{3}$. The following formula for calculating tumor volume was used: Length $\mathrm{x}$ width $\mathrm{x}$ (length+width /2) x 0.526. Three weeks post-injection, the animals were sacrificed with $\mathrm{CO}_{2}$ and the tumors were carefully dissected. The tumors were measured using calipers and the following formula was used to calculate tumor volume: Tumor volume = length $\mathrm{x}$ width $\mathrm{x}($ length + width / 2) $\mathrm{x} 0.526$.

Reverse transcription-quantitative polymerase chain reaction $(R T-q P C R)$. Total RNA was isolated with TRIzol (Invitrogen Life Technologies) and $1 \mu \mathrm{g}$ RNA was used for reverse transcription with a SuperScript ${ }^{\circledR}$ VILO $^{\text {TM }}$ cDNA Synthesis kit (Invitrogen Life Technologies). SYBR Green Master mix (Clontech Laboratories, Inc., Mountain View, CA, USA) was used for the RT-qPCR reaction. RT-qPCR was performed using a cycler (Roche Mol, IND) and SYBR green dye. For data analysis, a method designated as $2^{-\triangle \Delta C T}$ was used to calculate fold changes. The following primers (Sangon Biotech Co., Ltd., Shanghai, China) were used: Forward: 5'-ATTGCCGACAGGATGCAGA-3' and reverse: 5'-GAGTACTTGCGCTCAGGAGGA-3' for $\beta$-actin; forward: 5'-TCAAAAACAGAGACGAAGGACA-3' and reverse: 5'-GATTCAAAGTGGCAGACAGGTT-3' for HIF-1 $\alpha$; forward: 5'GGGCCTCCGAAACCATGAACTT-3' and reverse: 5'-TCGCATCAGGGGCACACAG-3' for VEGF; forward: 5-'CAAACCTCCTCACAGCCCACT-3' and reverse: 5'-TGACACTGTCCAACTTGACCC-3' for c-Myc; forward: 5'-CACCTTTGATGGGTCCCTGTT-3 and reverse: 5'-CTGGCATACCTGTTGCTCACT-3' for Ets2; and forward: 5'-ACCACAGTCCATGCCATCAC-3' and reverse: 5'-TCCACCACCCTGTTGCTGT-3' for GAPDH. The cycling conditions were as follows: $95^{\circ} \mathrm{C}$ for $2 \mathrm{~min}$ for initial denatureation, 40 cycles of $95^{\circ} \mathrm{C}$ for $15 \mathrm{sec}$ and $60^{\circ} \mathrm{C}$ for $1 \mathrm{~min}$.

Western blotting. Western blotting was performed as previously described (11). Specific antibodies for HIF-1 $\alpha$ and c-Myc were purchased from Cell Signaling Technology, Inc. (Beverly, MA, USA). Following washing with rinse buffer, the blot membranes were incubated with 1:3,000 diluted horseradish peroxidase-conjugated secondary antibody (Santa Cruz Biotechnology, Inc., Dallas, TX, USA) and samples were then developed using enhanced chemiluminescence reagents (Amersham, Little Chalfont, UK).

Immunohistology. Tumor samples were isolated and immediately fixed in $10 \% \mathrm{pH}$-neutral phosphate-buffered formalin. The fixed tissues were then embedded in paraffin and kept until required. Paraffin sections $(4 \mu \mathrm{m})$ were cut, deparaffinized and hydrated. Antigens were retrieved in $10 \mathrm{mM}$ sodium citrate buffer ( $\mathrm{pH}$ 6.0) and preheated to $95^{\circ} \mathrm{C}$ for $10 \mathrm{~min}$. Immunohistochemical staining of the protein was performed using the streptavidin-peroxidase method with antibodies specific to HIF-1 $\alpha$ (rabbit polyclonal, cat. no. 3716; 1:1,000 dilution) and anti-VEGF mouse monoclonal antibody (cat. no. M727; 1:1,000; Clone VG1; Dakopatts, Copenhagen, Denmark). The stained sections were examined and scored using a microscope (Olympus IX51; Olympus, Hamburg, Germany). In order to measure microvessel density (MVD), paraffin-embedded and formalin-fixed sections were stained with anti-CD31 mouse monoclonal antibody (cat. no. 14-031893; 1:40; Dakopatts). The immunohistochemically-stained microvessels were counted in five areas with the highest vascular density per section of tumor, as described previously (12).

Microarray of gene expression. SW1990 cells treated with or without TL for $4 \mathrm{~h}$ were harvested and total RNA was isolated. cDNA probes were synthesized and labeled with Cy5-dCTP or Cy3-dCTP (Amersham Biosciences, Piscataway, NJ, USA) for TL-treated cells or control cells, respectively. A BiostarH-40s microarray (Biostar Genechip Inc., Shanghai, China) containing 4,097 human genes was used and the service was provide by Shanghai United Gene Group Ltd. (Shanghai, China). Data were collected using a ScanArray4000 scanner (Perkin-Elmer, Boston, MA, USA). GenePixPro3.0 (Axon Instruments, Union City, CA, USA) was used to analyze the differences in gene expression between TL-treated cells and control cells.

Statistical analysis. All data are expressed as the mean \pm standard deviation. The significance for the difference between groups was assessed by one-way analysis of variance using SPSS software version 11.5 (SPSS, Inc., Chicago, IL, USA). $\mathrm{P}<0.05$ was considered to indicate a statistically significant difference. 
A
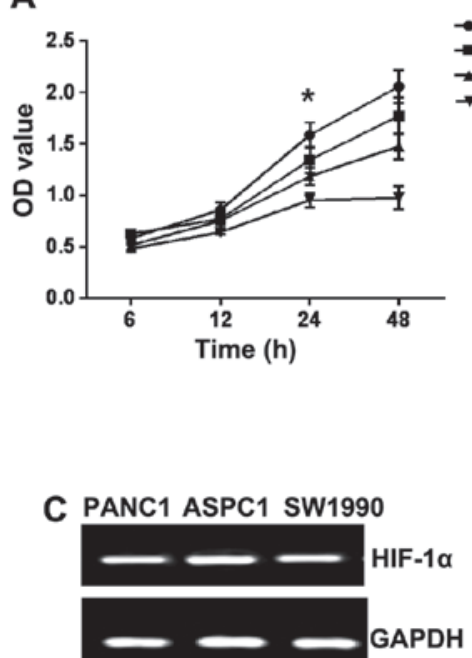

B

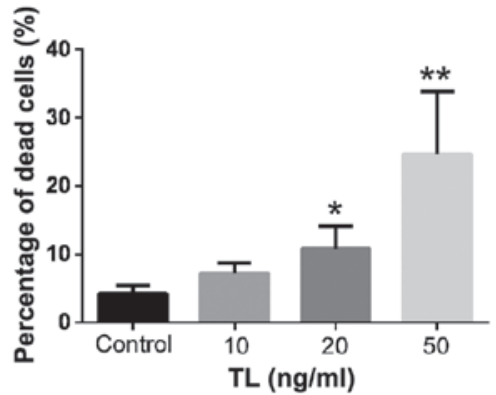

D TL (ng/ml) Control $10 \quad 20 \quad 50$ HIF-1a

Figure 1. TL inhibits growth of SW1990 cells and expression of HIF-1 $\alpha$. (A) Growth of SW1990 cells was measured after 6, 12, 24 and $48 \mathrm{~h}$ of TL treatment at concentrations of 10, 20 and $50 \mathrm{ng}$. Significant suppression of cell growth was initially observed after $24 \mathrm{~h}$ of treatment with $20 \mathrm{ng} / \mathrm{ml} \mathrm{TL}$. "P $<0.05$, compared with control. (B) TL induced cell death in SW1990 cells. ${ }^{*} \mathrm{P}<0.05$ and ${ }^{* *} \mathrm{P}<0.01$, compared with control. (C) Reverse transcription-polymerase chain reaction results indicated that HIF-1 $\alpha$ is expressed in the pancreatic cancer cell lines, PANC1, ASPC1 and SW1900. (D) HIF-1 $\alpha$ protein in SW1990 cells was detected using western blotting and its expression levels was reduced by TL in a dose-dependent manner. TL, triptolide; HIF-1 $\alpha$, hypoxia-inducible factor-1 $\alpha$; OD, optical density.
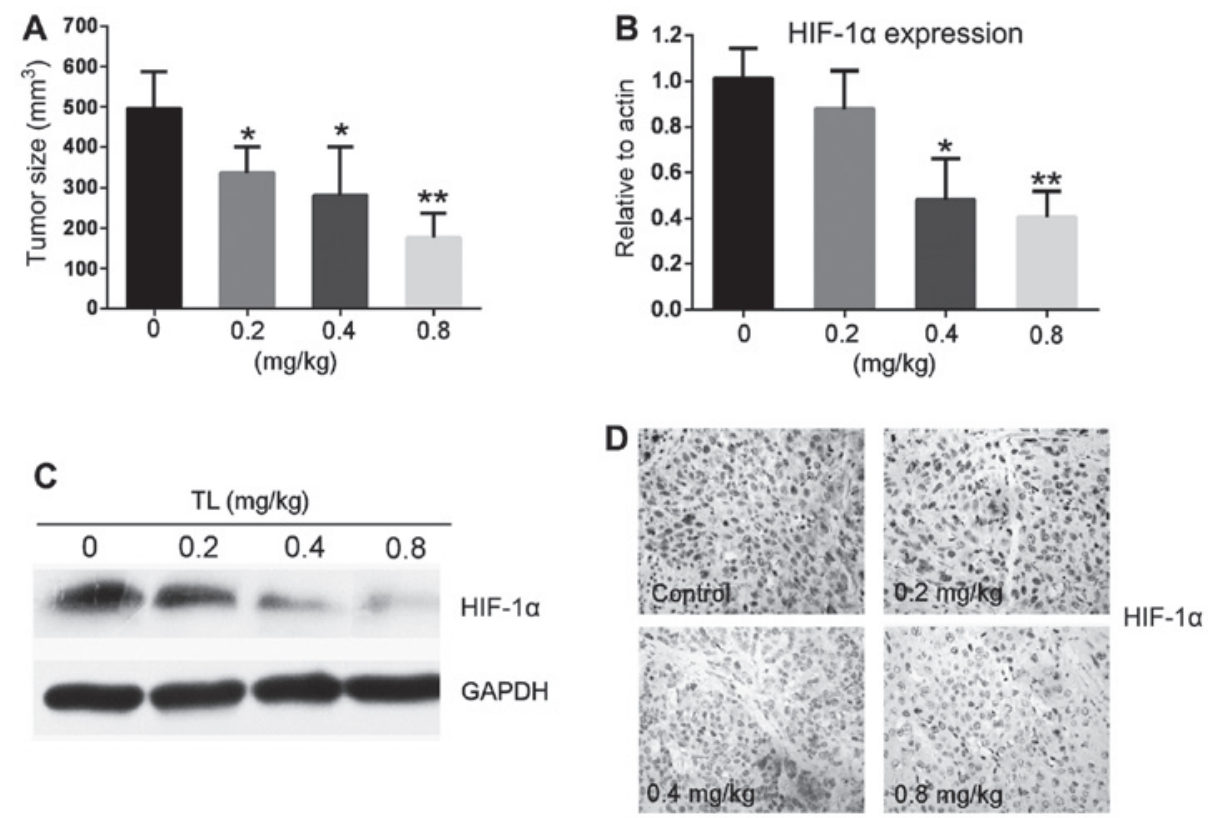

Figure 2. TL treatment suppressed pancreatic tumor growth and HIF-1 $\alpha$ expression in vivo. (A) The average tumor size for mice treated with varying doses of TL is shown and indicates that $0.2 \mathrm{mg} / \mathrm{kg}$ TL effectively suppressed tumor growth in vivo. Stronger antitumor effects were observed in the mice that received $0.8 \mathrm{mg} / \mathrm{kg} \mathrm{TL}$, which was indicated by markedly decreased tumor size by the end of the three-week treatment. " $\mathrm{P}<0.05$ and ${ }^{* * *} \mathrm{P}<0.01$, compared with the control group. N=8. (B) Reverse transcription-quantitative polymerase chain reaction results indicated that HIF-1 $\alpha$ expression was lower in tumor tissues from TL-treated mice than that in control mice. ${ }^{*} \mathrm{P}<0.05$ and ${ }^{* *} \mathrm{P}<0.01$, compared with the control group. In accordance with these results, the protein level of HIF-1 $\alpha$ was also reduced in TL-treated mice, which was measured using (C) western blotting or (D) immunohistology (magnification, x40) of labeled streptavidin biotin performed by immunohisotchemistry and diaminobenzidine. TL, triptolide; HIF-1 $\alpha$, hypoxia-inducible factor-1 $\alpha$.

\section{Results}

$T L$ reduces HIF-1 $\alpha$ expression in pancreatic cancer cells. The growth of the PANC1, ASPC1 and SW1990 pancreatic cancer cell lines following TL treatment was measured and compared with growth in these cells lines without TL. TL was found to induce cell death in all three cell lines (data not shown), with
SW1990 cells being the most sensitive to TL (Fig. 1A). At a concentration of $20 \mathrm{ng} / \mathrm{ml}$, TL led to a significant increase in the death of SW1990 cells after $24 \mathrm{~h}$ compared with the control cells (Fig. 1B). It has previously been reported that HIF-1 $\alpha$ is highly expressed in tumor tissues of patients with pancreatic cancer $(13,14)$. The present study tested the hypothesis that TL suppresses HIF-1 $\alpha$ expression in these cell lines, thereby leading 
Table I. Downregulated genes in SW1990 cells following triptolide treatment.

\begin{tabular}{lclc}
\hline Gene ID & Exp/Control & \multicolumn{1}{c}{ Gene name } & Abbreviation \\
\hline NM_002467 & 0.185 & V-myc myelocytomatosis viral oncogene homolog (avian) & c-MYC \\
NM_004655 & 0.285 & Axin 2 & AXIN2 \\
NM_000346 & 0.370 & SRY (sex determining region Y)-box 9 & SOX9 \\
NM_012242 & 0.390 & Dickkopf WNT signaling pathway inhibitor 1 & DLC38A2 \\
NM_018976 & 0.391 & Solute carrier family 38, member 2 & PDE1A \\
NM_005019 & 0.437 & Phosphodiesterase 1A, calmodulin-dependent & ETS2 \\
NM_005239 & 0.446 & V-ets erythroblastosis virus E26 oncogene homolog 2 (avian) & TGIF \\
NM_170695 & 0.453 & TGFB-induced factor (TALE family homeobox) & ID3 \\
NM_002167 & 0.477 & Inhibitor of DNA binding 3, dominant negative helix-loop-helix protein & HES1 \\
NM_005524 & 0.481 & Hairy and enhancer of split 1, (Drosophila) & DDIT4 \\
NM_019058 & 0.500 & DNA-damage-inducible transcript 4 & \\
\hline
\end{tabular}

Exp/Control is the ratio between TL-treated and control cells. As for c-Myc, the expression level was reduced to $18.5 \%$ in TL-treated cells compared with that of the control cells.
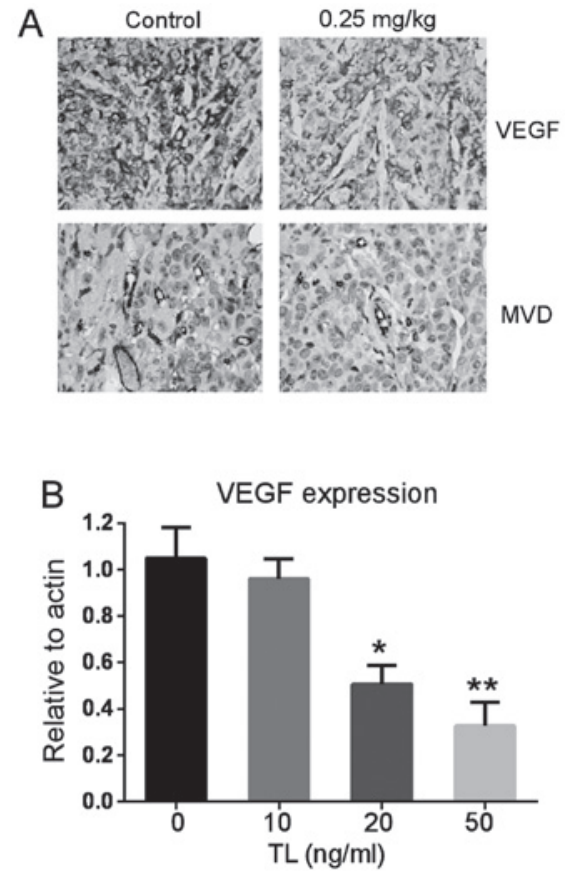

Figure 3. TL inhibited the expression of VEGF and MVD. (A) The expression of VEGF was reduced in tumor tissues from mice treated with $0.25 \mathrm{mg} / \mathrm{kg}$ $\mathrm{TL}$ as indicated by immunohistological staining. The MVD was also lower in tumor tissues from treated mice than that from control mice. Images (magnification, $\mathrm{x} 40$ ) of labeled streptavidin biotin performed by immunohisotchemistry and diaminobenzidine. (B) SW1990 cells were treated with 10,20 or $50 \mathrm{ng} / \mathrm{ml} \mathrm{TL}$ for $24 \mathrm{~h}$, and reverse transcription-quantitative polymerase chain reaction was performed in order to measure expression levels of VEGF. The results indicated that TL suppressed VEGF gene expression in SW1990 cell in a dose-dependent manner. ${ }^{*} \mathrm{P}<0.05$ and ${ }^{* * *} \mathrm{P}<0.01$, compared with control. TL, triptolide; VEGF, vascular endothelial growth factor; MVD, microvessel density.

to cell death. Using RT-qPCR, a substantial quantity of HIF-1 $\alpha$ transcription in all three cell lines was detected (Fig. 1C). Western blotting was performed in order to determine changes in the expression of HIF-1 $\alpha$ in SW1990 cells following treatment with TL. The results showed that HIF-1 $\alpha$ expression was
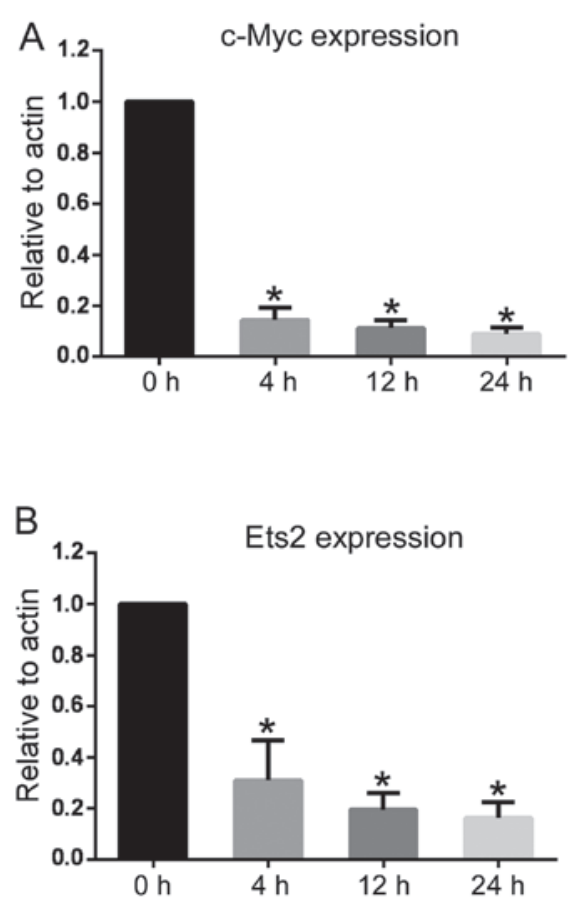

Figure 4. TL suppresses c-Myc and Ets2 gene expression. (A) RT-qPCR was performed in order to measure the expression level of the c-Myc gene after 4, 12 and $24 \mathrm{~h}$ TL treatment. The results indicated that TL markedly suppressed c-Myc gene expression following $4 \mathrm{~h}$ treatment, which was in accordance with the microarray data. (B) Downregulation of Ets2 in TL treated SW1990 cells was also confirmed using RT-qPCR. ${ }^{*} \mathrm{P}<0.01$, compared with control. TL, triptolide; RT-qPCR, reverse transcription-quantitative polymerase chain reaction.

suppressed at $24 \mathrm{~h}$ following TL treatment, and that this effect occurred in a dose-dependent manner as shown in Fig. 1D. These data suggest that HIF-1 $\alpha$ is highly expressed in pancreatic cancer cells lines and that downregulation of HIF-1 $\alpha$ may be responsible for cell death in pancreatic cell lines.

HIF-1 $\alpha$ expression in tumor tissues is downregulated following TL treatment. In order to test whether TL suppresses HIF-1 $\alpha$ expression in vivo, a xenograft model of pancreatic 
cancer was established using SW1990 cells. In the present study, the transplanted tumor was usually visible five days following injection of tumor cells, and grew to $\sim 100 \mathrm{~mm}^{3}$ by day 10 . From day 11 , TL at various doses was injected IP, daily for three weeks. The results confirmed that treatment with TL significantly suppressed tumor growth, as evaluated by tumor size at the end of treatment (Fig. 2A). Tumor tissues were collected and HIF-1 $\alpha$ expression levels were measured using RT-qPCR. The results demonstrated that HIF-1 $\alpha$ transcriptional levels in tumor tissues were significantly lower in mice that had been treated with TL, compared with those in control mice (Fig. 2B). HIF-1 $\alpha$ protein levels in these tumors were also measured using western blotting. As shown in Fig. 2C, the level of the HIF-1 $\alpha$ protein was significantly reduced following TL treatment. In accordance with this, immunohistological staining demonstrated that HIF-1 $\alpha$ expression was reduced in tumors from mice treated with TL, compared with that in the control group (Fig. 2D). No obvious side effects were observed in the mice treated with $0.2-0.4 \mathrm{mg} / \mathrm{kg}$ TL for 3 weeks, however certain side effects, including skin irritation, edema and bleeding of skin capillary vessels, were observed in a number of the mice treated with $>0.5 \mathrm{mg} / \mathrm{kg}$ TL.

TL suppresses vascular endothelial growth factor (VEGF) expression and microvessel density in tumor tissues. As TL was shown to suppress HIF-1 $\alpha$ expression, it was hypothesized that the expression of VEGF, which is a HIF-1 $\alpha$ target gene, may also be reduced following TL treatment. The expression of VEGF in tumor tissues from mice, with or without TL treatment, was therefore measured using immunohistological staining. As hypothesized, the results showed that the expression of VEGF was reduced in tumor tissues from mice treated with TL, compared with that in the control group (Fig. 3A, upper panel). In addition, TL reduced the MVD in tumor tissue, as shown in Fig. 3A (lower panel). The inhibitory effect of TL on the expression of VEGF in the SW1990 cell line was also significant when measured using RT-qPCR (Fig. 3B). These data indicate that TL suppresses the expression of HIF-1 $\alpha$ and inhibits its downstream function, such as the expression of VEGF and the regeneration of microvessels in tumor tissues.

TL treatment alters the expression levels of multiple cancer-related genes and signal transduction. In order to gain insight into the mechanisms underlying TL-mediated antitumor effects in pancreatic cancer, the gene expression profile in pancreatic cancer cells was examined following TL treatment. SW1990 cells were treated with $40 \mathrm{ng} / \mathrm{ml} \mathrm{TL}$ for $4 \mathrm{~h}$, and the expression level of 4,097 genes was measured. The results showed that the expression of 11 genes was downregulated in TL-treated cells compared with untreated cells, as shown in Table I. The most significant change was observed in the c-Myc gene, which was reduced to $10-20 \%$ of the level of that in the control group in TL-treated cells. Other genes that were downregulated include the oncogene Ets2, and certain transcription factors involved in tumorigenesis, such as SOX9 (15), dickkopf WT signaling pathway inhibitor 1 (16) and hairy and enhancer of split-1 (17). The marked change in the expression of the c-Myc gene is noteworthy, as c-Myc is a well-known oncogene, and its upregulation has been reported in numerous types of tumor (18-20). RT-qPCR was used to confirm data obtained from the microarray experiments. As shown in Fig. 4A and B, the expression of c-Myc and Ets2 was reduced following $40 \mathrm{ng} / \mathrm{ml}$ TL treatment for 4-24 h.

\section{Discussion}

TL treatment leads to cell death in a number of types of tumor cell line in vitro. In addition, it has potent antitumor effects in numerous animal models of cancer, and has potential for use as a chemotherapeutic agent (21-24). TL alters the expression of certain genes in different experimental settings and a significant effort has been made to investigate the common mechanism among them (25). A previous study indicated that TL inhibits $\mathrm{NF}-\kappa \mathrm{B}$ activity and the expression of its downstream genes (26), which are involved in inflammation and tumorigenesis. However, other studies have indicated that the spectrum of genes inhibited by TL may be considerably broader than that of $\mathrm{NF}-\kappa \mathrm{B}$ target genes. Recent reports have demonstrated that TL exerts global transcriptional inhibitory activity by inducing proteasome-dependent degradation of the largest subunit of RNA polymerase II in cancer cells (27-29). As a transcription inhibitor, the use of TL in patients should be carefully evaluated as potential side effects may occur as a result of non-specific inhibition of global transcription. We propose that two issues should be thoroughly investigated prior to its development as a chemotherapeutic agent.

Firstly, the side effects of TL require assessment in order to evaluate the tolerance of this drug throughout the course of treatment. In the present study, the xenograft mouse model of pancreatic cancer was shown to be tolerant to $0.2-0.4 \mathrm{mg} / \mathrm{kg}$ TL, and no obvious side effects were observed during the three weeks of treatment they received, compared with the control group. However, certain side effects, including skin irritation, edema and bleeding of skin capillary vessels, were observed in the present study in a number of the mice treated with $>0.5 \mathrm{mg} / \mathrm{kg}$ TL. Although these side effects were not life-threatening, it is likely that the combined use of low dose of TL with other therapeutic approaches may, in addition to delivering more potent antitumor effects, also minimize the side effects of TL that are experienced at higher doses.

Secondly, overexpression of oncogenes is known to initiate tumorigenesis, and to drive growth or metastasis of tumor cells. However, different oncogenes are involved in different tumor types. For example, the present study showed that c-Myc and HIF-1 $\alpha$ are constitutively overexpressed in pancreatic cancer cell lines and pancreatic tumor tissues. c-Myc is an oncogene and has been shown to be overexpressed in numerous types of tumor (30). However, HIF-1 $\alpha$ usually is induced by hypoxia and is not expressed in normoxic conditions, while it is highly expressed in pancreatic tumors and is associated with vessel generation in a number of tumor tissues (31). In accordance with recent reports $(13,14)$, the present study found that TL reduced HIF-1 $\alpha$ expression in pancreatic cancer cell lines and in a tumor mouse model, suggesting that HIF-1 $\alpha$ is involved in the development of pancreatic cancer. Furthermore, the current results indicate that the constitutive expression of HIF-1 $\alpha$ may be associated with a high level of c-Myc in pancreatic cancer cells, as suggested in a recent study on colon cancer (32). We hypothesize that overexpression of c-Myc and HIF-1 $\alpha$ increase the sensitivity of pancreatic tumor cells to TL compared with 
that of normal cells, thereby resulting in a more targeted effect of this treatment. Therefore, the pattern of expression of key oncogenes in certain types of tumor, may affect the sensitivity of cells to TL and thus the efficacy of this drug.

The duration of TL treatment may also be important, as c-Myc gene expression is suppressed at an early stage in pancreatic cancer cell lines, which indicated an approach by which to minimize side effects. That is, through short-term treatment rather than continued use of the drug. c-Myc overexpression is estimated to occur in $70 \%$ of human tumors (33). Furthermore, inhibition of c-Myc was recently demonstrated to be an effective method with which to treat lung cancer (34). These findings suggest that further investigation into the use of c-Myc as a target for tumor therapy is required $(18,35,36)$. Although the finding that the c-Myc gene is involved in the tumorigenesis of pancreatic cancer was not a novel one, the present study did show that c-Myc is a target of TL and its expression is markedly inhibited by treatment with TL for a duration over which the expression of the majority of genes is not affected. Further investigation is required to examine how to utilise this activity of TL in the treatment of patients with pancreatic cancer who exhibit high levels of expression of c-Myc.

\section{Acknowledgements}

This study was supported by the National Natural Scientific Grants, P.R. China (grant no. 81072028) and the Foundation for Key Medical Talents in Jiangsu Province (grant no. RC2007085).

\section{References}

1. Hidalgo M: Pancreatic cancer. N Engl J Med 362: 1605-1617, 2010.

2. Jemal A, Siegel R, Xu J and Ward E: Cancer statistics. CA Cancer J Clin 60: 277-300, 2010.

3. Castellanos E, Berlin J and Cardin DB: Current treatment options for pancreatic carcinoma. Curr Oncol Rep 13: 195-205, 2011.

4. Maitra A and Hruban RH: Pancreatic cancer. Annu Rev Pathol 3: 157-188, 2008.

5. Zhou GX, Ding XL, Huang JF, Zhang H, Wu SB, Cheng JP and Wei Q: Apoptosis of human pancreatic cancer cells induced by Triptolide. World J Gastroentero 14: 1504-1509, 2008.

6. Carter BZ, Mak DH, Schober WD, Dietrich MF, et al: Triptolide sensitizes AML cells to TRAIL-induced apoptosis via decrease of XIAP and p53-mediated increase of DR5. Blood 111: 3742-3750, 2008.

7. Chang WT, Kang JJ, Lee KY, et al: Triptolide and chemotherapy cooperate in tumor cell apoptosis. A role for the p53 pathway. J Biol Chem 276: 2221-2227, 2001.

8. Kulke MH: Systemic therapy for advanced pancreatic neuroendocrine tumors. Semin Oncol 40: 75-83, 2013.

9. Otrock ZK, Hatoum HA, Awada AH, Ishak RS and Shamseddine AI: Hypoxia-inducible factor in cancer angiogenesis: structure, regulation and clinical perspectives. Crit Rev Oncol Hematol 70: 93-102, 2009.

10. Semenza GL: HIF-1: upstream and downstream of cancer metabolism. Curr Opin Genet Dev 20: 51-56, 2010.

11. Ding X, Zhu C, Qiang H, Zhou X and Zhou G: Enhancing antitumor effects in pancreatic cancer cells by combined use of COX-2 and 5-LOX inhibitors. Biomed Pharmacother 65: 486-490, 2011

12. Weidner $\mathrm{N}$ : Intratumor microvessel density as a prognostic factor in cancer. Am J Pathol 147: 9-19, 1995.

13. Hoffmann AC, Mori R, Vallbohmer D, et al: High expression of HIF1a is a predictor of clinical outcome in patients with pancreatic ductal adenocarcinomas and correlated to PDGFA, VEGF, and bFGF. Neoplasia 10: 674-679, 2008.
14. Sun HC, Qiu ZJ, Liu J, et al: Expression of hypoxia-inducible factor-1 alpha and associated proteins in pancreatic ductal adenocarcinoma and their impact on prognosis. Int $\mathbf{J}$ Oncol 30: 1359-1367, 2007

15. Tanaka T, Kuroki T, Adachi T, et al: Evaluation of SOX9 expression in pancreatic ductal adenocarcinoma and intraductal papillary mucinous neoplasm. Pancreas 42: 488-493, 2013.

16. Gao C, Xie R, Ren C and Yang X: Dickkopf-1 expression is a novel prognostic marker for gastric cancer. J Biomed Biotechnol 2012: 804592, 2012.

17. Lee SH, Hong HS, Liu ZX, Kim RH, Kang MK, Park NH and Shin KH: TNF $\alpha$ enhances cancer stem cell-like phenotype via Notch-Hes1 activation in oral squamous cell carcinoma cells. Biochem Biophys Res Commun 424: 58-64, 2012.

18. Dang CV: MYC on the path to cancer. Cell 149: 22-35, 2012.

19. Gabay M, Li Y and Felsher DW: MYC activation is a hallmark of cancer initiation and maintenance. Cold Spring Harb Perspect Med 4: a014241, 2014.

20. Stellas D, Szabolcs M, Koul S, et al: Therapeutic effects of an anti-Myc drug on mouse pancreatic cancer. J Natl Cancer Inst 106: dju320, 2014.

21. Zhou ZL, Yang YX, Ding J, Li YC and Miao ZH: Triptolide: structural modifications, structure-activity relationships, bioactivities, clinical development and mechanisms. Nat Prod Rep 29: 457-475, 2012.

22. Alsaied OA, Sangwan V, Banerjee S, Krosch TC, Chugh R, Saluja A, Vickers SM and Jensen EH: Sorafenib and triptolide as combination therapy for hepatocellular carcinoma. Surgery 156 : 270-279, 2014

23. Carter BZ, Mak DH, Shi Y, Fidler JM, Chen R, Ling X, Plunkett W and Andreeff M: MRx102, a triptolide derivative, has potent antileukemic activity in vitro and in a murine model of AML. Leukemia 26: 443-450, 2012.

24. Ding X, Zhang B, Pei Q, Pan J, Huang S, Yang Y, Zhu Z, Lv Y and Zou X: Triptolide induces apoptotic cell death of human cholangiocarcinoma cells through inhibition of myeloid cell leukemia-1. BMC Cancer 14: 271, 2014.

25. Liu Q: Triptolide and its expanding multiple pharmacological functions. Int Immunopharmacol 11: 377-383, 2011.

26. Yinjun L, Jie J and Yungui W: Triptolide inhibits transcription factor NF-kappaB and induces apoptosis of multiple myeloma cells. Leuk Res 29: 99-105, 2005.

27. Titov DV, Gilman B, He QL, Bhat S, Low WK, Dang Y, Smeaton M, Demain AL, Miller PS, Kugel JF, et al: XPB, a subunit of TFIIH, is a target of the natural product triptolide. Nat Chem Biol 7: 182-188, 2011.

28. Vispé S, DeVries L, Créancier L, Besse J, Bréand S, Hobson DJ, Svejstrup JQ, Annereau JP, Cussac D, Dumontet C, et al: Triptolide is an inhibitor of RNA polymerase I and II-dependent transcription leading predominantly to down-regulation of short-lived mRNA. Mol Cancer Ther 8: 2780-2790, 2009.

29. Wang Y, Lu JJ, He L and Yu Q: Triptolide (TPL) inhibits global transcription by inducing proteasome-dependent degradation of RNA polymerase II (Pol II). PLoS One 6: e23993, 2011.

30. Meyer N and Penn LZ: Reflecting on 25 years with MYC. Nat Rev Cancer 8: 976-990, 2008.

31. Rankin EB and Giaccia AJ: The role of hypoxia-inducible factors in tumorigenesis. Cell Death Differ, 15: 678-685, 2008.

32. Chen C, Cai S, Wang G, Cao X, Yang X, Luo X, Feng Y and $\mathrm{Hu} \mathrm{J}$ : c-Myc enhances colon cancer cell-mediated angiogenesis through the regulation of HIF-1 $\alpha$. Biochem Biophys Res Commun 430: 505-511, 2013

33. Gordan JD, Thompson CB and Simon MC: HIF and c-Myc: sibling rivals for control of cancer cell metabolism and proliferation. Cancer Cell 12: 108-113, 2007.

34. Soucek L, Whitfield JR, Sodir NM, Massó-Vallés D, Serrano E, Karnezis AN, Swigart LB and Evan GI: Inhibition of Myc family proteins eradicates KRas-driven lung cancer in mice. Genes Dev 27: 504-513, 2013.

35. Soucek L, Whitfield J, Martins CP, Finch AJ, Murphy DJ, Sodir NM, Karnezis AN, Swigart LB, Nasi S and Evan GI: Modelling Myc inhibition as a cancer therapy. Nature 455: 679-683, 2008

36. Sodir NM, Swigart LB, Karnezis AN, Hanahan D, Evan GI and Soucek L: Endogenous Myc maintains the tumor microenvironment. Genes Dev 25: 907-916, 2011. 